\title{
Influence of Irrigating Solutions on Push-Out Bond Strenght of Intraradicular Posts to Dentine
}

\section{Influencia de diferentes soluciones de irrigación en la resistencia de unión de los postes intra-radiculares a la dentina}

\author{
Mohammad Kaif DDS'; Raj Bissu DDS, MSc \\ 1. Uttar Pradesh, India \\ Correspondence to: Dr. Raj Bissu - rbissu@india.com \\ Received: 28-I-2016 \\ Accepted: 17-III-2016 \\ Published Online First: 18-III-2016
}

DOI: http://dx.doi.org/10.15517/ijds.v0i0.23557

\begin{abstract}
The aim of this study was to evaluate the influence of irrigating solutions commonly used during endodontic treatment on the push-out bond strength of intrarradicular fiber posts to dentin. Thirty single rooted teeth were divided into 3 groups according to the solution used during instrumentation: G1, NaOCL $5.25 \%$; G2, 2\% chlorhexidine; G3, distilled water. The root canals were prepared and obturated, and the glass fiber posts were cemented with RelyX ARC $\circledast$. The specimens were submitted to push-out bond test and the results were analyzed by using the One-way ANOVA. The failure mode data were analyzed using the Chi-square test $(P<0.05)$. There were no statistically significant differences regarding the irrigant solution factor $(P>0.50)$. The most predominant failure mode was between posts and resin cement. It was concluded that the different irrigant solutions commonly used in endodontic treatment did not affect the push-out bond strength of fiber posts cemented with resin cement.
\end{abstract}

\section{KEYWORDS}

Sodium hypochlorite; Chlorhexidine; Push-out test; Intra-radicular fiber posts. 


\section{RESUMEN}

El objetivo de este estudio fue evaluar la influencia de las soluciones de irrigación comúnmente utilizadas durante el tratamiento endodóntico en la resistencia de unión de postes de fibra intraradiculares a la dentina. Treinta dientes humanos uniradiculares fueron divididos en 3 grupos de

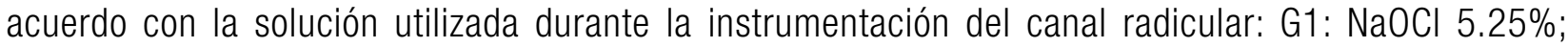
G2: 2\% gluconato de clorhexidina; G3: agua destilada. Los conductos radiculares fueron conformados y obturados, y los postes de fibra de vidrio fueron cementados con cemento a base de resina. Las muestras fueron sometidas al test de push-out y los resultados se analizaron mediante ANOVA. Los datos de los modos de fallo se analizaron mediante la prueba de Chi-cuadrado $(P<0,05)$. No hubo diferencias estadísticamente significativas considerando la solución de irrigación $(P>0,50)$. El modo de falla más predominante fue en la interface entre los postes y el cemento de resina. Basados en los resultados obtenidos en este estudio se concluye que las diferentes soluciones de irrigación utilizadas comúnmente en el tratamiento endodóntico no afectaron la resistencia de unión de los postes de fibra cementados con cemento de resina.

\section{PALABRAS CLAVE}

Hipoclorito de sodio; Clorexidina; Push-out test; Postes de fibra de vidrio.

\section{INTRODUCTION}

The innovations in restorative dentistry over the last decade have contributed significantly to improving the quality of the restorations of roottreated teeth in order to obtain a better long term prognosis (1). Endodontically treated teeth are more vulnerable to fracture than vital teeth because of loss of tooth structure and structural integrity as a consequence of decays, change in dentine, and access preparation (1). Thus, rehabilitation with intrarradicular post is often essential (2).

Nowadays, cementation of fiber posts in root canal still a challenge. Adhesion is a complex of physical and chemical mechanisms that allows the attachment of one substance to another (3). Despite major improvements in the lasts decades regarding adhesive dentistry, bonding to intraradicular dentin remains an unpredictable goal due to several clinical factors influencing the procedure (4). Moreover, adhesive fiber posts cementation have as a pre-requisite the endodontic treatment.
Several factors may affect adhesion to intraradicular dentin: presence and thickness of the endodontic smear layer, post space preparation, effect of different chemicals used such as endodontic irrigants and/or endodontic filling materials which clearly modify dentin substrate (4). Several articles on literature associate intra-radicular posts failures to post/resin cement debonding (3-5). However dentin/cement/post interface failure is more admitted to occurred $(2,4-7)$.

Over the lasts years, dentin/resin cement debonding was attributed to the different irrigating solutions used during endodontic treatment, such as sodium hypochlorite or chlorhexidine $(8,9)$. Although sodium hypochlorite is the most used and preconized endodontic irrigant, if used in association with resin based materials can cause some alterations due to its oxidizing properties (4). Sodium hypochlorite leaves a dentin surface characterized by an oxygen-rich layer that can significantly reduce bond strength and increase nano and micro leakage (10-12). Bear in mind 
that the dentin/resin cement interface bonding durability is critical for the endurance of adhesive cementation of intrarradicular posts and final restoration, it seems critical to understand the influence of common irrigating solutions used during endodontic treatment. Thus, the aim of this study was to evaluate the influence of sodium hypochlorite and chlorhexidine on the push-out bond strength of intrarradicular fiber posts to dentin.

\section{MATERIALS AND METHODS}

Thirty single-rooted human teeth, extracted for orthodontics treatment from subjects between 15 to 40 years old were used in this study. The inclusion criteria were: absence of root caries and/ or root crack and/or previous restoration and/or endodontic treatment, and straight root with at least $13 \mathrm{~mm}$ length. Teeth were cleaned with an ultrasonic scaler and store in $0.5 \%$ chloramin $\mathrm{T}$ solution at $4^{\circ} \mathrm{C}$ and used them within 3 months following extraction. The crowns were sectioned at the cement-enamel junction with the aim of the diamond disk (Degussa Dental, Hanau, Germany) in a slow speed hand piece, under water-cooling.

The teeth were divided in three groups $(n=10)$ regarding the irrigating solution used during the endodontic treatment:

- Group 1: 5,25\% sodium hypochlorite

- Group 2: 2\% chlorhexidine

- Group 3: Distilled Water (control group)

All root canals were instrumented by a working length of $1 \mathrm{~mm}$ from the apex. Cleaning and shaping were performed with nickel-titanium rotary instrumentation (S1, S2, and F3, Protaper; Dentsply Maillefer, Ballaiguse, Switzerland). The root canal was irrigated between instrumentation with $1 \mathrm{ml}$ of their respective solution totalizing 5 $\mathrm{ml}$, and finally dried using absorbent paper points (Ariadent, Iran). The smear layer removal was performed with the irrigation with $3 \mathrm{ml}$ of $17 \%$ EDTA. Each root canal was obturated using lateral compaction with gutta-percha points (Ariadent, Iran) and AH Pus sealer (Dentsply Maillefer, Ballaiguse, Switzerland). The accesses were temporized with Cavite (Ariadent, Iran). The roots were stored in $100 \%$ moisture at $37^{\circ} \mathrm{C}$ for $24 \mathrm{~h}$.

The post space preparation was performed with a Gates Glidden drill \#3 (Dentsply/Maillefer, Ballaigues, Switzerland) to remove the gutta percha, leaving 3-4 $\mathrm{mm}$ of gutta percha in the apical third of the specimens. Post space preparation was done with a \#5 Peasso reamer (Dentsply/Maillefer, Ballaigues, Switzerland). Final rinsing was done with distilled water.

FibreKor ${ }^{\circledR}$ post (Jeneric/Pentron Inc., USA) with $1.25 \mathrm{~mm}$ in diameter was used in this study. The posts were cleaned with $70 \%$ isopropyl alcohol and allowed to dry for 1 minute. The post space was dried with multiple paper points.

Each post space was etched with phosphoric acid as indicated by manufacturer. Adper Single Bond 2 (3M ESPE Products, St. Paul, MN, USA) was applied with microbrushes (Dentsply/Maillefer, Ballaigues, Switzerland) and was left undisturbed for 10 seconds, and then a gentle blast of air was administered using a three-way syringe. The bonding agent was light cured with an LED light-curing unit (SDI, Bayswater, Victoria, Australia) for 20 seconds.

Equal amounts of the two pastes of RelyX'M ARC (3M ESPE products, St. Paul, MN, US) were dispensed onto the mixing pad and mixed. The cement was then applied on to the root canal walls with the aid of Lentulo $®$ spiral (Dentsply/ Maillefer, Ballaigues, Switzerland). The cement was also applied onto the posts with the spatula. The posts were then seated in the post space with firm finger pressure. The excess cement was removed gently. The cement was light cured using an LED 
light-curing unit for 20 seconds from the coronal end of the posts. All the specimens were stored in distilled water at $37^{\circ} \mathrm{C}$ for 24 hours in an incubator.

\section{PUSH-OUT TEST}

Each root was sectioned in order to obtained standardized $1 \mathrm{~mm}$-thick slices. The first slice in coronal and the last in the apical area was discarded. Finally, we had one piece for each root area (coronal, middle, apical). The apical face of each slice was marked with permanent color ink. The thickness of each slice was checked by digital caliper.

The test specimen slices were fixed in the fitting device fitted to the universal testing machine (Zwick Z010, Germany). The 0.8-mm diameter tip was placed over the smallest base of the test specimen and a compression force was applied in an apical-coronal direction at a cross-head speed of $0.5 \mathrm{~mm} /$ minute until the post piece was dislocated. The peak value of the load required for dislocating the post from the specimen was recorded in Newtons. The push-out strength (MegaPascals $=$ MPa) was calculated.

\section{MODE OF FAILURE}

The fractured slices were assessed at $\times 30$ magnification under stereomicroscope (Nikon type 102, Nikon Crop, Tokyo, Japan) to classify: (1) Adhesive failure between post \& resin cement (no cement around the post); (2) Adhesive failure between dentine \& resin cement (post enveloped by resin cement); (3) Mixed, with resin cement covering $0 \%$ to $50 \%$ of the post diameter; (4) Mixed, with resin cement covering $50 \%$ to $100 \%$ of the post diameter; (5) Cohesive in post; (6) Cohesive in dentine. Randomly selected slices were reexamined using scanning electron microscopy (SEM) for illustrating.

\section{STATISTICAL ANALYSIS}

The mean and standard deviations of bond strength were calculated and the data were analyzed using the One-way ANOVA and Scheffe post-hoc test. The failure mode data were analyzed using the Chi-square test. The accepted level of errors was set at $\mathrm{P}<0.05$.

\section{RESULTS}

The mean bond strength values of the fiber post to root dentin for the experimental and control groups are summarized in Table 1. The highest and the lowest bond strength mean values were found respectively in G3 and G1 (39.60 vs. 38.29 MPa). However, no significant differences in bond strength were found between the groups $(P>0.05)$. The mean and SD excluded premature failure and voided specimen.

Table 1. Mean and standard deviation (MPa) of bond strength following push out testing.

\begin{tabular}{ccc}
\hline Group & MPa & SD \\
\hline G1 & 38.29 & 21.54 \\
G2 & 38.95 & 12.16 \\
G3 & 39.60 & 14.76 \\
\hline
\end{tabular}

Table 2 shows the failure modes observed in each group. Failure modes of all groups demonstrated that the majority of the bond failure was in an adhesive between post and resin cement. The comparison of the failure modes in each group using the chi-square test indicated no statistical difference between the groups.

SEM evaluation showed in figure 1 adhesive failure between dentin/resin cement interface. Figure 2 demonstrates a mixed failure with some fiber posts on residual resin cement. The most predominant failure mode was adhesive between post and cement. 
Table 2. Failure modes in each group (\%).

\begin{tabular}{cccccc}
\hline \multirow{2}{*}{ Group } & \multicolumn{2}{c}{ Failure } & Modes (\%) & \\
\cline { 2 - 5 } & $\begin{array}{c}\text { Adhesive (post- } \\
\text { cement) }\end{array}$ & $\begin{array}{c}\text { Adhesive (cement- } \\
\text { dentin) }\end{array}$ & Mixed & $\begin{array}{c}\text { Cohesive } \\
\text { (in post) }\end{array}$ & $\begin{array}{c}\text { Cohesive } \\
\text { (in dentin) }\end{array}$ \\
G1 & 50 & 30 & 20 & 0 & 0 \\
G2 & 60 & 10 & 30 & 0 & 0 \\
G3 & 60 & 20 & 20 & 0 & 0 \\
\hline
\end{tabular}

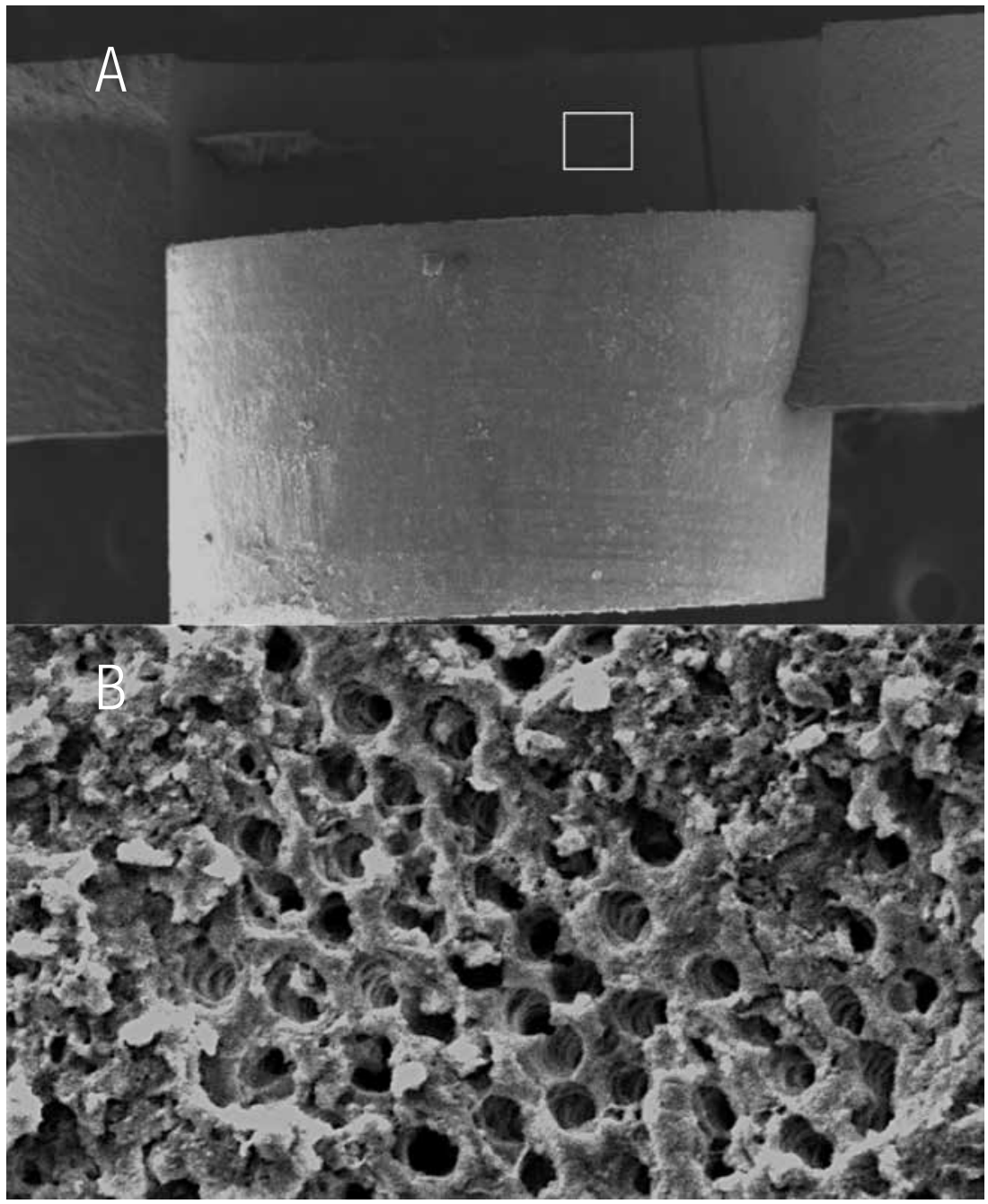

Figure 1. A. SEM Photomicrograph 500X of adhesive failure between dentin/resin cement interface from Group 1. B. Higher magnification (2000x) of the square in A. denote some dentinal tubules orifices demonstrating failure between the adhesive/resin cement/dentin. 


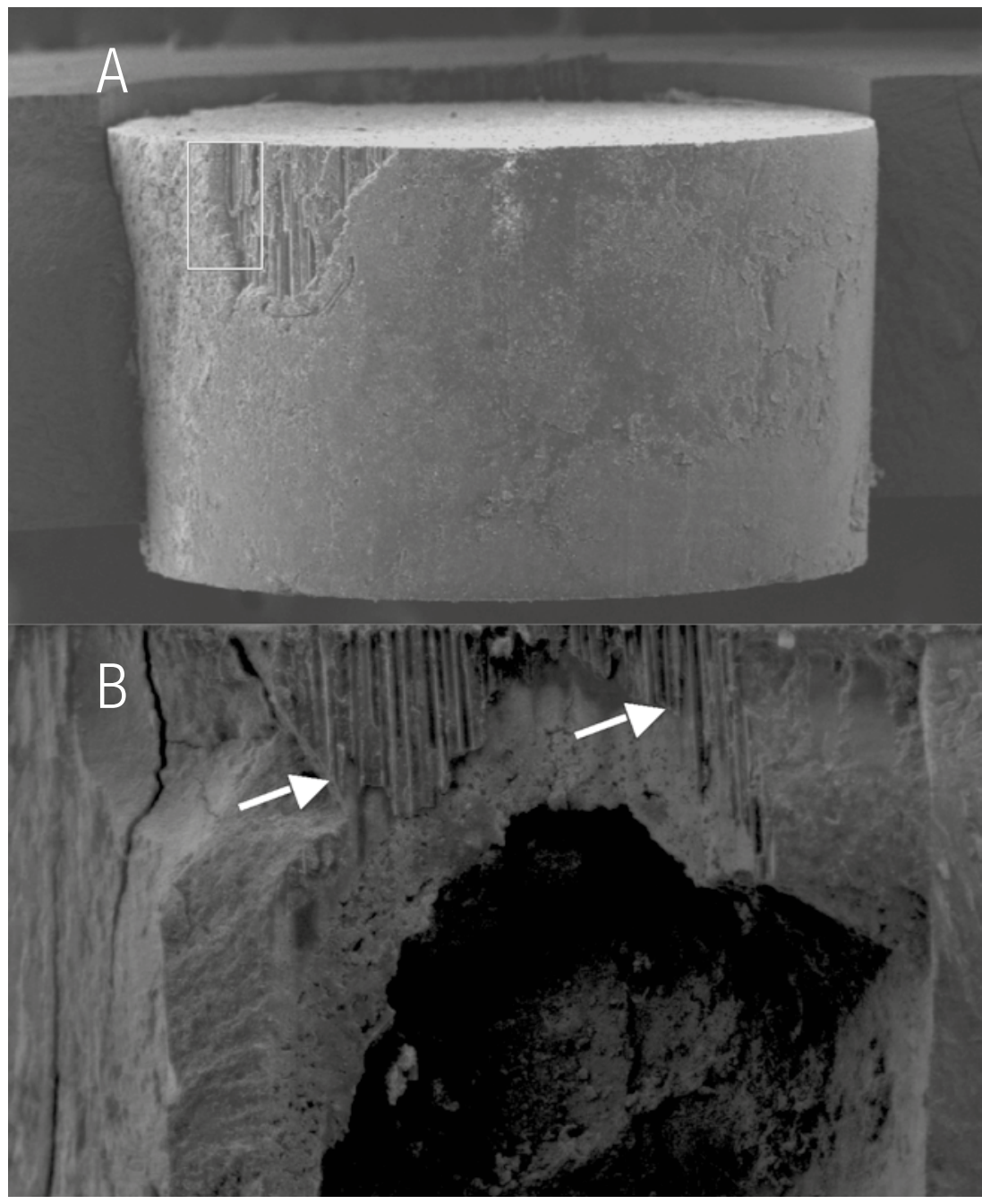

Figure 2. A. SEM Photomicrograph (80X) of a fiber post plug after displacement during pushout bond test. B. SEM Photomicrograph (1000X) of the square in A showing a mixed failure with some fibers within the resin cement layer(red arrows).

\section{DISCUSSION}

Despite constant improvements in dental substrate adhesion, bonding to intra-radicular dentin remains a challenge (5). Adhesive cementation with fiber posts in endodontic treated teeth is necessary to provide the retention for the core of a definitive restoration (11). Prefabricated glass fiber posts have been increasingly used because its modulus of elasticity is similar to that of dentin, in addition to a favorable esthetic factor (12).
The major factors affecting post retention are dentin substrate, post dimensions (length, diameter), shape (conical, cylindrical), type of surface (serrated, screw, smooth), intracanal space preparation, dentin surface treatment, type of cement, and operator skills (13).

Studies have investigated composition and structure of the intra-radicular dentin (14). Besides just minor morphological and biochemical differences were found between coronal and 
intra-radicular dentin, studies showed major differences in the bond strength when comparing both substrates $(4,14)$. Intra-radicular dentin, as coronal dentin, also is characterized by the presence of peritubular and intertubular tissue (14). Notwithstanding that the number of tubules in the root canal diminish toward the apical region leading to a substrate modification that will induce changes within each procedure performed during endodontic treatment and adhesive cementation of fiber posts.

In addition to the difficulty to control the substrate surface, several other factors may affect adhesive procedures to intra-radicular dentin, such as the use of irrigants or medicaments during the endodontic treatment. Thus, our study evaluated the influence of sodium hypochlorite or chlorhexidine, common irrigating solutions used during endodontic treatment, on the push-out bond strength of intra-radicular fiber posts to dentin.

During irrigation, radicular and coronal dentin are exposed to various chemical solutions to disinfect the endodontic space (4). Thereby, this endodontic procedure may affect dentin surface and consequently their interactions with resin based materials (15). Its well known that the oxidizing action of sodium hypochlorite leads to residual-free oxygen within the dentin matrix that may critically interfere with the initiation of the resin cements polymerization leading to poor bond strengths (16). An additional side effect of sodium hypochlorite irrigation is the significant reduction in the microhardness of root canal dentin $(15,17)$. This reduction demonstrates the direct effects of this chemical solution to dentin, which affect the adhesion and sealing ability of sealers to the softened chemical treated dentin surfaces (17). On the other hand, $0.2 \%$ chlorhexidine gluconate has harmless effect on the microhardness and roughness of root canal dentin (17), and showed highest bond strength when compared to sodium hypochlorite $(4,18)$.
In our study, the results showed that the irrigating solutions used during endodontic treatment did not affect the bond strength of the adhesive fiber posts cementation procedure. One possible explanation for our results must be that independently of the irrigating solution used during the instrumentation phase of the endodontic treatment, all specimens were treated with the same smear layer irrigating protocol. The most common protocol to remove smear layer, before obturation, is the irrigation with $3 \mathrm{ml}$ of $17 \%$ EDTA. EDTA conditioning provides smear layer removal with no denaturation of collagen, which prevents the collapse of the collagen network (19). It displays a mild decalcifying capacity and minor influence on the dentine, due to the avoidance of denaturation of collagen, in part to the presence of more residual apatite crystals left in collagen matrix (20-21). Moreover is commonly recognized that $17 \%$ EDTA is a chelating solution that may act as a reducing agent (19). A previous study showed that solutions that may act as reducing agent, such as 10\% ascorbic acid, have been effective to reverse the compromised bond obtained on sodium hypochlorite treated dentin (16). According to Morris et al. (16), by treating dentin with a reducing agent, the intra-radicular dentin substrate is converted from an oxidized to a reduced surface, speculating that this treatment restores the redox potential of the dentin and facilitates the polymerization of the resins.

Moreover, the most predominant failure mode observed in our study was in the interface between post/resin cement, proving that the major failure or attention must be given to the chemical interaction between the outer layer of fiber posts and the cementation agent. This result must be controversial, taking in consideration that our methodology includes proper post surface cleaning with 70\% isopropyl alcohol, however no silane or ceramic was used in the posts to surface. This last issue must influence our failure mode results and would be a subject of a future study. 


\section{CONCLUSION}

According to the results presented in this study, we concluded that the different irrigant solutions commonly used in endodontic treatment did not affect the push-out bond strength of fiber posts cemented with resin cement. Special attention must be given to the interaction or bonding procedure of the fiber posts/resin cement interface.

\section{REFERENCES}

1. Al-Omiri M. K., Mahmoud A. A., Rayyan M. R., Abu-Hammad O. Fracture resistance of teeth restored with post-retained restorations: An overview. J Endod. 2010;36:1439-49.

2. Demiryürek E. O., Külünk S, Saraç D., Yüksel G., Bulucu B. Effect of different surface treatments on the push-out bond strength of fiber post to root canal dentin. Oral Surg Oral Med Oral Pathol Oral Radiol Endod. 2009;108:e74-80.

3. Cagidiaco, M.C., Goraci, C., García-Godoy, F. y Ferrari, M. Clinical studies of fiber posts: a literatura review. Int J Prosthodont, 21 (4), 2008: 328-336.

4. Ferrari, M. Fiber posts and Endodontically treated teeth: A compedium of scientific and clinical perspectives. Modern Dentistry Media. Europe. 2008.

5. Toman M., Toksavul S., Sarikanat M., Firidinoğlu K., Akin A. The evaluation of displacement resistance of glass FRC posts to root dentine using a thin slice push-out test. Int Endod J. 2009;42:802-10.

6. Goracci C., Tavares A. U., Fabianelli A., Monticelli F., Raffaelli O., Cardoso P. C., et al. The adhesion between fiber posts and root canal walls: Comparison between microtensile and push-out bond strength measurements. Eur J Oral Sci. 2004;112:353-61.
7. Bouillaguet S., Troesch S., Wataha J. C., Krejci I., Meyer J. M., Pashley D. H. Microtensile bond strength between adhesive cements and root canal dentin. Dent Mater. 2003;19:199-205.

8. Jha Padmanabh, Jha Mesha. Retention of fiber posts in different dentin regions: An in vitro study. Indian J Dent Res 2012;23:337-40.

9. Mathias P., Muniz L. The influence of sodium hypochlorite and root canal sealers on post retention in different dentin regions. OperDent 2005;30:533-9.

10. Lindblad R. M., Lassila L. V., Salo V., Vallittu P. K., Tjäderhane L. Effect of chlorhexidine on initial adhesion of fiber-reinforced post to root canal. J Dent. 2010;38:796-801.

11. Ari H., Yasar E., Belli S. Effects of NaOCL on bond strenght of resin cements to root canal dentin. J Endod 2003; 29:248-251.

12. Poggio C., Chiesa M., Lombardini M., Dagna A. Influence of ethanol drying on the bond between fiber posts and root canals: SEM analysis. Quintessence Int. 2011;42:e15-21.

13. Akkayan B., Gulmez T. Resistance to fracture of endodon- tically treated teeth restored with different post systems. J Prosthet Dent 2002;87(4):431-7.

14. Ferrari M., Mannocci F., Vichi A., Cagidiaco M. C., Mjor I. A. Bonding to root canal: structural characteristic of the substrate. Am J Dent 2000; 13:255-260.

15. SalehA.A.,Ettman W.M.Effect of endodontic irrigationsolution on microhardness of root canal dentine. J Dent 1999;27:43-46.

16. Morris M. D., Lee K. W., Agee K. A., Bouillaguet S, Pashley DH. Effects of sodium hypochlorite and RC-Prep on bond strenghts of resin cement to endodontic surfaces. J Endod 2001;27:753-757.

17. Ari H., Erdemir A., Belli S. Evaluation of the effect of enodontic irrigating solutions on 
the microhardness and the roughness of root canal dentin. J Endod 2004;30:792-795.

18. Oncag O., Hosgor M., Hilmioglu S., Zekioglu O., Eronat C. et al. Comparison of antibacterial, bond and toxic effects of various root canal irrigants. Int Endod J 2003;36:423-432.

19. Alfredo E., de Souza E. S., Marchesan M. A., Paulino S. M., Gariba-Silva R., Sousa-Neto MD.Effect of Eugenol-Based Endodontic Cement on the Adhesion of Intraradicular Posts. Braz Dent J 2006;17:130-3.
20. Sauro S., Toledano M., Aguilera F. S., Mannocci F., Pashley D. H., Tay F. R., et al. Resin-dentin bonds to EDTA-treated vs. acidetched dentin using ethanol wet-bonding. Part II: Effects of mechanical cycling load on microtensile bond strengths. Dent Mater. 2011;27:563-72.

21. Osorio R., Erhardt M. C., Pimenta L. A., Osorio E., Toledano M. EDTA treatment improves resin-dentin bonds' resistance to degradation. J Dent Res. 2005;84:736-40. 